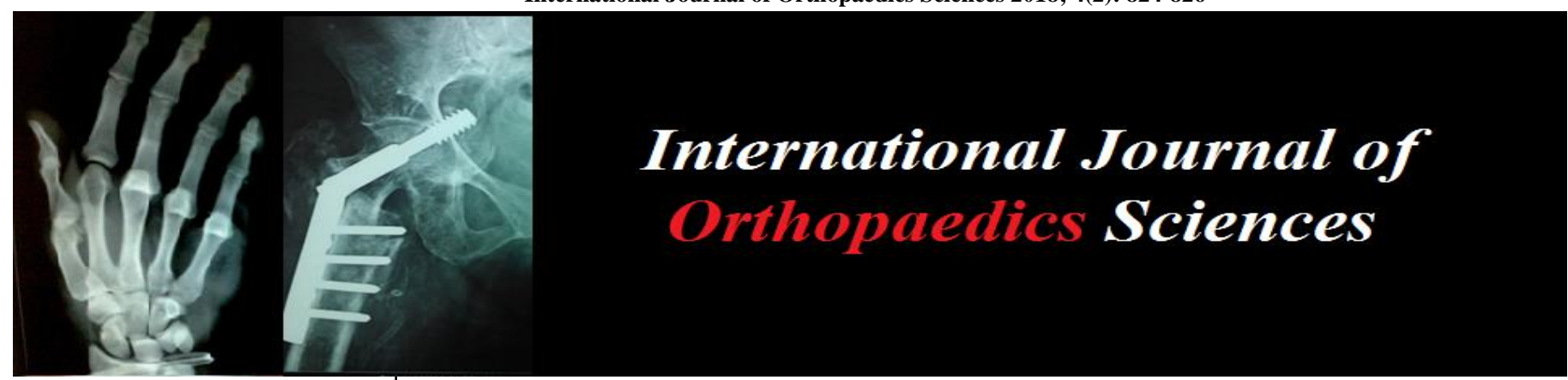

ISSN: $2395-1958$

IJOS 2018; 4(2): 824-826

(C) 2018 IJOS

www.orthopaper.com

Received: 20-02-2018

Accepted: 21-03-2018

Dr. Susheel Soni

Assistant Professor,

Department of Orthopaedic,

IMCHRC Indore,

Madhya Pradesh, India

Dr. Deepak Mantri

Associate Professor,

Department of Orthopaedic,

MGMMC, Indore,

Madhya Pradesh, India

\section{Evaluation of postoperative complication after PHILOS plating for treatment of displaced proximal humerus fractures}

\section{Dr. Susheel Soni and Dr. Deepak Mantri}

DOI: $\underline{\text { https://doi.org/10.22271/ortho.2018.v4.i21.120 }}$

\section{Abstract}

Objective: Evaulation of the complications from surgical treatment using a proximal humerus locking plate among patients with fractures of the proximal humerus.

Methods: This is a non Randomised Retrospective and Prospective study carried out from 1 July 2017 to 30 December 2018. In this study a cohort of 30 patients from this institute and other hospital, all skeletally matured patients aged 18 years and above with proximal humerus fractures with two, three, four part fracture were treated using the PHILOS plate. There were 19 male patients and 11 female patients, with a mean age of 49.5 years (range: 18 to 81 years). All the cases had a mean postoperative follow up period of 15 months. Eight fractures were classified as presenting in two parts, 13 as three, 9 as four.

Results: In this study, twelve were considered to have achieved excellent results, nine good, eight fair and one poor, according to the UCLA score. In our study of PHILOS plating most common complication was varus malunion and least common complication was implant failure.

Conclusion: The functional results from treating fractures of the proximal extremity of the humerus using a locking plate depended on correct anatomical reduction of the fracture and stable fixation of the implant. Complications still occur frequently, particularly because of intraoperative technical difficulty, fracture severity and possible inexperience of the surgeon.

Keywords: PHILOS Plate, proximal humerus

\section{Introduction}

Proximal humeral fractures are now recognized as an increasingly common fracture, accounting for $4 \%$ to $5 \%$ of all fractures ${ }^{[1,2]}$. It is the third most common fracture in people above 65 years of age, after fractures of the hip and distal radius ${ }^{[3]}$. These fractures have a bimodal distribution occurring either in young people following high energy trauma or in those older than 50 years with low velocity injuries like simple fall ${ }^{[3]}$. They occur most commonly in elderly patients, after cancellous bone of humeral neck has weakened by senility. Proximal humerus fractures are the result of an indirect force such as a fall onto the outstretched arm rather than a direct blow to the shoulder. The origin of a proximal humerus fracture is due to a combination of factors, which include relatively osteoporotic bone (in the elderly), direct contact against the adjacent acromion and glenoid rim, and forceful pull of the rotator cuff muscles and extrinsic muscles such as the pectoralis major ${ }^{[4]}$.

Traditional internal fixation stabilisation methods for proximal humeral fractures include semirigid (percutaneous k-wiring, screw fixation, tension band wiring) and rigid (conventional plates and screws, intramedullary nailing) ${ }^{[5-16]}$ means. The proximal humeral internal locking system (PHILOS) is a new implant designed for the fixation of proximal humeral fractures and is one of a new generation of locking plates ${ }^{[17,18]}$. Its shape is anatomical, conforming to the proximal humerus. In the humeral head component of the plate, locking screws are inserted in multiple directions into the humeral head. In the shaft component of the implant combi-holes provide the option of locking or nonlocking screws to be inserted. Smaller holes allow the passage of sutures or wires to help reattachment of the greater and lesser tuberosities. The implant comes in short and long sizes with three and four shaft combiholes, respectively. The aim of this study was to describe early results of this implant, in particular potential implant related complications.
Correspondence

Dr. Susheel soni

Assistant Professor,

Department of Orthopaedic,

IMCHRC Indore,

Madhya Pradesh, India 


\section{Material \& method}

This is a non Randomised Retrospective and Prospective study carried out at Department of Orthopaedics \& traumatology, Index Medical College, Hospital \& Research Centre, Indore from 1 july 2017 to 30 December 2018. In this study a cohort of 30 patients (ninteen male and eleven female) from this institute and other hospital, all skeletally matured patients aged 18 years and above were included. Eight fractures were classified as presenting in two parts, thirteen as three, nine as four part. In this study a mean age is 49.5 years (range: 18 to 81 years). All the cases had a mean postoperative followup period of 15 months All patients with proximal humerus was admitted to the hospital, all history and clinical details were recorded in history sheet according to planned Proforma. Radiographic evaluation was done and fractures were classified according to Neer's classification. All routine investigations were done with complete medical and anaesthetic fitness for surgery. All patients were treated by open reduction and internal fixation by PHILOS plating. Patients with One part fracture, pediatric age group, Pathological fractures, Compound fractures, uncontrolled diabetes, patients on chronic steroid therapy and Immunocompromised patients were excluded from study.

Surgical technique: - Preoperative planning is done for every cases. We used standard deltopectoral approach. This approach can be a fairly extensile approach, allowing access to the anterior, medial, and lateral aspects of the shoulder. This approach is done in a supine position with a roll or wedge under the medial scapula. An incision is made following the line of the deltopectoral groove size depends on the surgical need and size of patient. The deltopectoral fascia is encountered first; the cephalic vein is surrounded in a layer of fat and is used to identify the interval. The cephalic vein can be mobilized either medially or laterally, depending on patient factors and surgeon preference. Fibers of the deltoid are retracted laterally and the pectoralis major is retracted medially. The short head of the biceps and coracobrachialis arise from the coracoid process and are retracted medially. The musculocutaneous nerve enters the biceps $5-8 \mathrm{~cm}$ distal to the coracoid process; retraction of the conjoint tendon must be done with care. The fascia on the lateral side of the conjoint tendon is incised to reveal the subscapularis. External rotation puts the subscapularis fibers on stretch. The subscapularis may be released from its insertion on the lesser tuberosity through the tendon or via an osteotomy. The capsule is then incised (as needed) to enter the joint. Reduce the fracture and provisionally fix it with kwires; confirm reduction with fluoroscopy. If medial communition is present, check to ensure that varus malreduction has not occurred. Place the plate onto the greater tuberosity \& provisionally fix it with k- wires; confirm correct plate position with fluoroscopy. Place two locking screws through the plate holes into the humeral head and one or two screws into the shaft. Confirm subchondral placement of proximal screws with fluoroscopy. When accurate reduction is confirmed insert remaining screws under direct fluoroscopic control. The wound closure done after putting a suction drain, to be removed 24-48 hours later.

\section{Results \& observations}

In our study of 30 patients, treated by PHILOS and follwed up for minimum 15 month and maximum follow up available is 24 month. In this study, twelve were considered to have achieved excellent results, nine good, eight fair and one poor, according to the UCLA score. In our study of PHILOS plating most common complication was varus malunion and least common complication was implant failure.

Table 1

\begin{tabular}{|c|c|c|}
\hline Complications & No. Of Patients & Percentage \\
\hline Joint stiffness & 2 & 6.7 \\
\hline Implant failure(Pull out of screws, implant breakage) & Nil & Nil \\
\hline Primary and secondary screw perforations & 2 & $6.7 \%$ \\
\hline Sub acromial impingement & 1 & $3.3 \%$ \\
\hline Avascular necrosis of humeral head & 1 & $3.3 \%$ \\
\hline Infection, controlled by antibiotic & 2 & $6.7 \%$ \\
\hline varus Malunion & 3 & $10 \%$ \\
\hline Non-union & Nil & Nil \\
\hline
\end{tabular}

\section{Discussion}

Proximal humerus fractures are more common in older age group ${ }^{[28]}$ because cancellous bone of the humeral neck has weakened by senility. In our study $60 \%$ patients were from 50 to 70 years age group. Numerous age related studies points towards this and our study is consistent with this.

Table 2

\begin{tabular}{|c|c|c|}
\hline Study & Age of patients studied & Mean age \\
\hline Roland P. Jacob $^{[19]}$ & $24-81$ & 49.5 \\
\hline C.Gerber,C. M. L.Werner $^{[20]}$ & $16-73$ & 44.9 \\
\hline Wijgman,W. Roolker $^{[21]}$ & $19-79$ & 48 \\
\hline Evan L. Flatow, Francis Cuomo $^{[2]}$ & $34-72$ & 53 \\
\hline P. Moonot et $^{\left[{ }^{[23]}\right.}$ & $18-87$ & 59.9 \\
\hline Our Study & $18-70$ & 49.5 \\
\hline
\end{tabular}

As with earlier studies, our study showed a higher incidence of proximal humerus fracture in males compared to females. The gender ratio in our study was $1.73: 1$ which is quite higher than other studies. High ratio can be explained by a more involvement of males in day to day activities as compared to female.
Table 3

\begin{tabular}{|c|c|c|}
\hline Study & Male & Female \\
\hline Roland P. Jacob $^{[19]}$ & 1.57 & 1.0 \\
\hline C. Gerber, C. M. L. Werner $^{[20]}$ & 1.35 & 1.0 \\
\hline Evan L. Flatow, Francis Cuomo $^{[22]}$ & 1.40 & 1.0 \\
\hline Our study $^{|c|}$ & 1.73 & 1.0 \\
\hline
\end{tabular}


In consistent with the majority of studies in western literature that consider low energy falls as a more common cause for proximal humerus fractures, our study had $80 \%$ patients with history of fall. Low energy trauma can cause significant injury in elderly patient with osteoporotic bones.

There are different surgical options for the fixation of proximal humeral fractures, e.g., interfragmentary fixation with sutures, percutaneous pinning, intramedullary fixation and hemiarthroplasties. Fixation of proximal humeral fractures with plates and screws has been associated with complications such as pull out of screws in osteoporotic bone, subacromial impingement and avascular necrosis of the humeral head due to excessive periosteal stripping. Kristiansen and Christensen ${ }^{[33]}$ had reported a high incidence of fixation failure following use of $\mathrm{T}$-buttress plates in fixation of proximal humeral fractures.

\section{Conclusion}

Fractures of the upper end of humerus account for $4-5 \%$ of all fractures. They occur more frequently in older patients after the cancellous bone has become weakened by senility and osteoporosis. In older patients even less severe trauma (fall) can produce significant injury which is the most common cause. In our study $60 \%$ belongs to 51 to 70 years age group. Fall on ground account for $77 \%$ of proximal humerus fractures in our study. PHILOS plates are pre-shaped \& precontoured plates to match proximal humeral anatomy with multiple proximal locking screw placement options has made fixation of complex fractures easy. It provides rigid fixation, enhanced axial \& angular stability \& allows early mobilization of the shoulder without compromising fracture union. Proximal humerus locking plate fixation for 2-part and 3-part fractures has better functional outcome Compare to Complicated four Part Fractures. Functional Outcome is better and earlier in Younger Patients. Although outcome is also good in elderly. Age and fracture configuration play a significant role in the clinical outcome of these fractures after internal fixation.

\section{References}

1. Palvanen M, Kannus P, Niemi S, Parkkari J. Update in the epidemiology of proximal humeral fractures. Clin Orthop. 2006; 442:87-92.

2. Spence RJ. Fractures of the proximal humerus. Curr Opin Orthop. 2003; 14:269-80.

3. Baron JA, Barrett JA, Karagas MR. The epidemiology of peripheral fractures. Bone. 1996; 18(3):209S-13S.

4. Jon warner JP, John G. Costouror, Christian Gerger. Fractures of proximal humerus In Rookwood and Green s fracture in adults $6^{\text {th }}$ edition lippincott William ad wilkim, 1161-1209.

5. Agel J, Jones CB, Sanzone AG, Camuso M, Henley MB. Treatment of proximal humeral fractures with polarus nail Wxation. J Shoulder Elbow Surg. 2004; 13:191-195

6. Bernard J, Charalambides C, Aderinto J, Mok D. Early failure of intramedullary nailing for proximal humeral fractures. Injury. 2000, 2004; 31:789-792

7. Burton D, Wells G, Watters A, Schilders E, Venkateswaran B. Early experience with the PlantTan Wxator plate for 2 and 3 part fractures of the proximal humerus. Injury 2005; 36:1190-1196. 210 Arch Orthop Trauma Surg. 2007; 127:205-210.

8. Hintermann B, Trouillier H, Schafer D. Rigid internal Wxation of fractures of the proximal humerus in older patients. J Bone Joint Surg Br. 2000; 8:1107-1112.
9. Kristiansen B, Christensen SW. Plate Wxation of proximal humeral fractures. Acta Orthop Scand. 1986; 57:320-323.

10. Machani B, Sinopidis C, Brownson P, Papadopulos P, Gibson J, Frostick SP. Mid term results of Plant Tan plate in the treatment of proximal humeral fractures. Injury. 2006; 37:269-276.

11. Rajasekhar C, Ray P, Bhamra M. Fixation of proximal humeral fractures with the polarus nail. J Shoulder Elbow Surg. 2001; 10:7-10.

12. Robinson CM, Christie J. The two part-proximal humeral fracture: a review of operative treatment using two techniques. Injury. 1993; 24:123-125.

13. Robinson CM, Page R. Severely impacted valgus proximal humeral fractures. J Bone Joint Surg Am. 2003; 9:1647-1655.

14. Sadowski C, Riand N, Stern R, HoVmeyer P. Fixation of fractures of the proximal humerus with the PlantTan humerus Wxator plate: early experience with a new implant. J Shoulder Elbow Surg. 2003; 12:148-151.

15. Wijgman A, Roolker W, Patt T, Raaymakers E, Marti R. Open reduction and internal Wxation of three and four part fractures of the proximal part of the humerus. J Bone Joint Surg Am. 2002; 84:1919-1924.

16. Zyto K, Ahrengart L, Sperber A, Tornkvist H. Treatment of displaced proximal humeral fractures in elderly, 1997.

17. Haidukewych GJ. Innovations in locking plate technology. J Am Acad Orthop Surg. 2004; 12:205-212.

18. Perren S. Backgrounds of the technology of internal Wxators. Injury. 2003; 34:S-B1, S-B3S.

19. Roland Jakob $\mathrm{P}$ et al. Four part valgus impacted fractures of the proximal humerus. JBJS Br. 1991; 73-B:29.

20. Gerber $C$, Werner CML, Vienne $P$. Internal fixation of complex fractures of the proximal humerus. JBJS Br. 2004; 86-B: 848-853. 5-297.

21. Wijgman Roolker, Patt Raaymakers, Marti. Open reduction and Internal fixation of three and four part fractures of the proximal part of the humerus. JBJS (Am). 2002; 84-A:1919-1920.

22. Evan Flatow L, Frances Cuomo, Michael, Seth, Stephen, Louis Bigliani. Open Reduction and Internal fixation of two part displaced fractures of the greater tuberosity of proximal part of the humerus. JBJS (Am). 91, 73-A, 8:1213-1214.

23. Moonot P, Ashwood N, Hamlet M. Early results for treatment of three- and four- part fractures of the proximal humerus using the PHILOS plate system.J Bone Joint Surg [Br]. 2007; 89-B:1206-9. 